\title{
Folk Mereology is Teleological
}

\author{
DAVID Rose \\ Rutgers University \\ JONATHAN SCHAFFER \\ Rutgers University
}

When does mereological composition occur? For instance, if a paper plate is positioned on a table between a plastic knife and a metal fork, does this scattered plurality of diverse objects make up a single composite object (a 'table setting') or not? Or if two people shake hands, does this connected plurality of similar objects make up a single composite object (shaped like a sculpture of two people shaking hands) or not? In general, when does a collection of things form a whole? Many metaphysicians have wanted a view of composition that respects folk intuitions, and have charged leading views with failing on this score. For instance, Hirsch (2002: 60) declares that 'the linguistic evidence indicates that fluent speakers of English do not speak the mereologist's language.' And Markosian (1998: 211) sets out from the claim that 'no one has yet defended a view... consistent with standard, pre-philosophical intuitions about the universe's composite objects.'

Yet there is widespread disagreement among metaphysicians as to what the folk intuit about mereological composition and why they do so, and no empirical discipline to the debate. We see this situation as an opportunity to put the tools of experimental philosophy to constructive use. Accordingly we aim to discover when the folk tend to think that composition occurs, and why they do so. So our question is: when do the folk think that mereological composition occurs? That is, what is folk mereology, against which metaphysical accounts of real mereology might be measured?

Our question - beyond whatever intrinsic interest it might possess - should be of interest to anyone interested in the psychological question of how humans conceptualize the world, and in the connected project of descriptive metaphysics. Whether our question is also relevant to prescriptive metaphysics is controversial. For those who take conformity with folk intuitions to be at least one desideratum of theory choice in prescriptive metaphysics, our question bears obvious relevance. But even those who would dismiss folk intuitions as irrelevant to real metaphysics (either because they deny that intuitions should play any role, or because they deny that the intuitions of the folk should play any role) may still want to know what they would dismiss. Indeed, it seems to us that understanding folk mereology is a precondition to considering whether it deserves to be taken seriously. 
Our own view is twofold. First, we hold that folk mereology is teleological, in that the folk tend to think that composition occurs in restricted circumstances, in which the question of whether the plurality has a purpose plays a major role. So, for instance, we predict that people will tend to say that composition has occurred with the knife, fork, and plate (since they collectively serve as a table setting) but not with the two people shaking hands (unless they are accorded a collective function). This view seems not even to be considered in the contemporary discussion, though it coheres with a wide swath of current psychological work on object concepts. Secondly, we regard such a folk theory as tied into a benighted teleological view of nature, and thus fit for debunking. As such we think that understanding folk mereology should actually lead us to liberate the discussion of when composition really occurs from any demanded conformity with folk intuitions. On this matter, the folk deserve to be ignored.

Overview: In $\S 1$ we review the existing discussion about when composition occurs, with an eye to claims that have been made about what the folk think. In $\S 2$ we review current psychological work on object cognition and promiscuous teleology, with an eye to documenting the extent to which the folk worldview is teleological. In $\S 3$ we use the methods of experimental philosophy to extract a teleological account of folk mereology, articulate some of the details, and connect this to current psychological research. Finally in $\$ 4$ we address methodological issues about the role of folk intuitions in real metaphysics, having (we hope) achieved sufficient understanding of folk mereology to see why it should be ignored.

\section{Composition and Intuition}

When does mereological composition occur? The metaphysical debate often centers on claims about what common sense would say. Yet there is disagreement about what common sense would say and why it would say so, and no empirical discipline to the debate.

\subsection{The special composition question}

When does mereological composition occur? That is, under what conditions does some plurality of individuals $X$ s compose some one individual $y$ ? This question is what van Inwagen (1990: 30) calls the 'special composition question,' and it has set the agenda for one of the main debates in metaphysics spanning the last two decades.

Strictly speaking, we-following van Inwagen - are focused on a question that is more restricted in two respects. First, we are only focused on when composition occurs for material objects. So in what follows all quantifiers should be read as restricted to material objects (unless the local context makes obvious otherwise). Perhaps mereological composition can occur among events or among abstract objects or among entities of some other sort, or even across categories of objects. Such is not our concern. ${ }^{1}$ Secondly, we are only interested in when many make one. It is standard to use 'plurality' in a way that is actually number neutral, allowing for pluralities of one or more individuals. With 'degenerate pluralities' of just a single 
individual, it is - at least on one usage of terms - trivial that composition occurs (everything composes itself). It is smoother to state the views in ways that ignore degenerate pluralities, and so we follow suit. Bringing this together, a more explicit formulation of our question is: under what conditions does some non-degenerate plurality of material objects $X$ s compose some one material object $y$ ?

The literature offers a wide variety of proposed answers to the special composition question. Perhaps the most standard answer is always, under any condition whatsoever. This is the answer of the Universalist (built into the classical mereology of Lesniewski and Goodman (cf. Simons 1987: 37-41), and defended by Lewis 1991). A second sort of answer to this question is never, under no condition whatsoever. This is the answer of the Nihilist (explored by Rosen \& Dorr 2002, and recently advocated by Sider 2013). Various intermediate answers are considered as well, such as sometimes, when the plurality is in contact, and sometimes, when the activities of the plurality constitute a life (the former is van Inwagen's first 'representative answer,' and the latter is his final considered position).

Without further discussion, we will simply tabulate various answers in the current literature. This table is not intended to be exhaustive, but just to illustrate the main options under consideration: ${ }^{2}$

Universalism (Lesniewski, Goodman, Composition always occurs Lewis)

Nihilism (Rosen \& Dorr, Sider)

Contact (van Inwagen's first illustrative view)

Fastening (van Inwagen's second considered view)

Vitalism (van Inwagen's final considered view)

Emergentism (Merricks)

Regionalism (Markosian's latter view)

Serialism (Sanford)

Brutalism (Markosian's earlier view)

Composition never occurs

Composition occurs when the plurality is in contact

Composition occurs when the plurality is fastened together

Composition occurs when the activities of the plurality constitute a life

Composition occurs when the plurality exhibits novel and irreducible collective powers

Composition occurs when the fusion of the regions occupied by the plurality is occupied by an individual

Composition occurs if the plurality is so and this condition is met, or if the plurality is such and that condition is met, or if the plurality is thus and the other condition is met, or ...

Composition occurs when it does, as a brute matter of fact 


\subsection{The role of folk intuitions}

Virtually every single view on the table as to when composition occurs has been charged with violating common sense, though the charges are usually disputed. In this vein Markosian (2014: §2) charges the main views with generating 'wildly counterintuitive consequences' and so evincing 'mereological madness.' In the interests of brevity we will focus on the role of intuitions in the debate over Universalism.

It is often said that Universalism posits bizarre fusions which common sense would reject. Here is a representative quote, from Hirsch (2002: 60):

I understand perfectly well what it means to talk (in plain English) about such things as cars, bees, human beings, books, and the Eiffel Tower, or even to talk about such marginal things as noses and car-hoods. But it's crazy to say (in plain English) that there exists something composed of my nose and the Eiffel Tower.

Indeed Markosian (1998: 228) considers this sort of charge to be 'a fatal objection' to Universalism, and Kriegel (2011: 198) tells us what the folk will think: 'Commonsense shuns [arbitrary] fusions, but... mereological universalists ... embrace them. The folk's intuitive verdicts will be against 'there is a fusion of this table and the moon'...'

But the friends of Universalism usually reject this charge. As Korman (2008: 320; cf. van Inwagen 1990: 75) observes: '[U]niversalists typically take the view to be entirely compatible with what the folk say in ordinary discourse about material objects.' In this vein, Lewis (1991: 80), discussing the fusion of the front of a trout with the back of a turkey, explains away hesitation to affirm existence via quantifier domain restriction:

Only if you speak with your quantifiers wide open must you affirm the trout-turkey's existence. If, like most of us all the time and all of us most of the time, you quantify subject to restrictions, then you can leave it out.

And in a slightly different vein, Thomasson-who (2007: 3) explicitly aims to show 'how, reflectively, we can make sense of our unreflective common sense worldview'maintains (2007: 183) that the folk simply have no view one way or another on arbitrary sums, never having considered them:

Certainly it is true that common sense does not recognize the existence of gollyswoggles, mereological sums, and the like. Nor, of course, does it deny their existence-There are no terms in ordinary English for these things, and common sense understandably does not consider such things at all, since given our current range of practices, such entities would be quite irrelevant and uninteresting.

Indeed she (2007: 184) then speculates that if 'we explained to 'normal' people' a term for some arbitrary sum, and then asked them if there is such a thing, they 'would certainly accept that there is.'

So we find a debate over what the folk think. Is Universalism a form of 'mereological madness' or 'entirely compatible with what the folk say'? We see little hope in settling this debate without empirical work. 
We could easily spend many more pages documenting further appeals to folk intuitions in the debate as to when composition occurs, but will instead just flag some main points:

- virtually every answer to the special composition question (not just Universalism) has been charged with violating folk intuitions, ${ }^{3}$

- metaphysicians have moreover constructed psychological theories about why the folk have the intuitions they allegedly have, ${ }^{4}$ and

- teleological notions are almost entirely absent from the current debate, including when the metaphysicians are speculating about what intuitions the folk have and why they have them.

Just on the last point: teleological notions do not come up when metaphysicians are presenting their own theories. ${ }^{5}$ This is not so surprising: orthodoxy has it that teleological notions are a vestige of an obsolete conception of nature-'part of a superseded, pre-scientific muddle about how the world works' (Hawthorne \& Nolan 2006: 267; cf. Jenkins \& Nolan 2008) - and thus unfit for real metaphysics. What is more surprising is that teleological notions do not come up even when metaphysicians are speculating about what the folk think. It almost seems as if the metaphysicians regard teleology as being so muddled that they cannot charitably imagine the folk wallowing in it.

\subsection{Aristotelian roots}

While teleological notions are almost entirely absent from the current debate, we would be remiss not to mention their roots in a broadly Aristotelian worldview. ${ }^{6}$

For Aristotle, substances are composites of matter and form, where the form plays the role of unifying the parts of a composite substance. The form unifies the parts of a composite substance by lending them a unified purpose: the parts become one because they act for the sake of a common end. This is the perspective that Aristotle seems to take when defending natural teleology in Physics (Aristotle 1984a: 340; Phys199a.30-33), saying: '[S]ince nature is twofold, the matter and the form, of which the latter is the end, and since all the rest is for the sake of the end, the form must be the cause in the sense of that for the sake of which.' And this perspective is perhaps most explicit when Aristotle is explaining the many senses in which things are called one in Metaphysics, in the course of which he (1984b: 1605; Meta1016b.12-16) specifies the sense in which something is called one as 'a whole,' which he glosses in terms of having 'one form,' and illustrates with the example of the shoe: '[I]f we saw the parts of a shoe put together anyhow we should not call them one...; we do this only if they are put together so as to be a shoe and have thereby some one form.'

We are not alone in finding a teleological account of composition in Aristotle. We find Charles's (2001: 100) discussion of Aristotle on unity especially clear on this point:

[I]t is the presence of a final cause which makes the relevant planks and bricks into a house. Being a house, on this view, cannot be reduced to being a mereological sum of 
bricks and planks. There is more to its unity than that of the sum of its components and their physical interrelations; for merely to specify these is to ignore the goal whose attainment is required if there is to be a house... Houses are the result of the operation of the final cause as a principle which organizes the relevant type of matter...

So we see in Aristotle a teleologically-laden view on when composition occurs, and thus want to credit Aristotle with delivering an account that proves to be insightful for folk metaphysics (even if that rules it out for real metaphysics).

\section{Psychological Context}

Empirical work on folk mereology need not begin ex nihilo. For while there is no psychological work that specifically considers the special composition question, there is a rich body of psychological work surrounding our object concepts, which ought to guide informed inquiry into folk mereology. A major theme emerging in this psychological work is the extent to which the folk worldview is teleological. We have a deep-seated tendency to view not just animals but all of nature - every rock and cloud - as infused with agency and purpose. As Dawkins (1995: 96) observes: 'We humans have purpose on the brain. We find it hard to look at anything without wondering what it is 'for,' what the motive for it is, or the purpose behind it.'

It is fairly well-established that when it comes to object categorization-saying what sort of thing something is - people tend to associate what something is with what it is for. Against this psychological background, our thesis can be understood as the thesis that people also tend to associate whether something is with whether there is something it is for.

\subsection{Selective teleology: artifacts and organisms}

It is widely accepted that we are at least 'selectively teleological,' in that our artifact and organism concepts are infused with notions of purpose and function. Most of the relevant psychological work concerns principles of object categorization (how we determine what a thing is). With both artifacts and organisms, we tend to identify what a thing is with what it is for.

So starting with artifact concepts, as German \& Johnson (2002: 279-280) note, it is well established that people take 'the design stance, in which an entity's properties, behavior, and existence is explained in terms of its having been designed to serve a particular purpose.' Likewise Bloom (1996: 3), reviewing earlier work by Rips and by Keil, notes: 'This has suggested to many scholars that the psychological 'core' of artifact concepts is that their members share a common intended function.' To illustrate, Rips (1989) found that adults judge that an object that looks like a lampshade is actually an umbrella when they are told that it was originally designed to protect people from rain.

With artifact concepts, there is a robust debate over the developmental details. For instance, Kelemen (1999a) argues that children take the design stance as early as four, Matan \& Carey (2001) argue for a more complicated developmental process in which the design stance is not fully in place until six years of age, and German 
\& Johnson (2002) argue for a different developmental process in which the ability to use an integrated adult-level design stance continues to develop in the period between five to seven years of age. We are only interested in adult competence, which all sides agree is based on the design stance, and we remain neutral on how and when this competence develops.

Turning to the organism concepts of 'folk biology,' it is well established that we strongly tend towards teleological thinking in this domain as well. For instance Keil (1995: 245) writes:

Historically there have been many arguments for a 'design' stance, which can include teleological interpretations and tool construction and use... Notions of functional architecture are among the most cognitively compelling ways of approaching the biological world and much of the artificial world as well, ...

Likewise Atran (1998: 550-551) speaks of the folk idea of a 'biological essence' as 'an intrinsic... teleological agent, which physically... causes the biologically relevant parts and properties of a generic species to function and cohere 'for the sake of' the generic species itself.'

Again there is robust debate concerning 'folk biology,' as to the extent to which biological cognition is domain-specific (perhaps subserved by a partially encapsulated 'folk biology module') or an application of more general-purpose cognition. And there is debate concerning the details of how we naturally organize the biological world hierarchically. ${ }^{7}$ Again we remain neutral on these debates, maintaining only the minimal and uncontroversial claim that organism concepts are teleologically infused.

\subsection{Promiscuous teleology}

So far we have discussed object categorization with artifact and organism concepts. One might think, in accord with the approach that Kelemen (1999a: 243) calls 'selective teleology,' that teleological thinking is largely restricted to these domains. But, as Kelemen (1999a: 244) argues, the more psychologically plausible view is that of 'promiscuous teleology,' according to which teleological thinking is not restricted:

[T]he teleological stance derives from children's understanding of agency and intentional object-directed behavior and may never become entirely autonomous from the intentional domain... [D]ue to these origins the teleological stance is applied broadly rather than selectively early in development: Infants may start out generally assuming that objects exist to be used by agents in some way and subsequently, in lieu of alternative explanations, develop the teleological belief that virtually all sorts of living and non-living entities are intentionally caused for a purpose. Children may only begin to revise and restrict this belief once they begin to assimilate more formal scientific ideas.

Indeed Kelemen (1999a: 245) goes on to note a historical tendency to view all of nature as an artifact:

[T]hroughout history, non-living natural objects have also been considered in such [teleological] terms... The earth, its climates, landforms, water sources, and elements, 
were seen as intentionally designed to create a habitat for, and meet the needs of, people. In other words, natural objects of all kinds - particularly those fulfilling a significant function in people's lives - were candidates for construal as quasi-artifacts.

Moreover Kelemen \& DiYanni (2005; cf. Kelemen 2004) report a strong tendency among children - both from religious and nonreligious backgrounds - to an 'intuitive theism' in which nature is viewed as an artifact of a creator, as well as a significant correlation between viewing something teleologically and regarding it as created. So one should expect teleological thinking to extend through to our general conception of an object. As Bloom (2007: 150) — in an article entitled 'Religion is Natural'-summarizes:

One of the most interesting discoveries in the developmental psychology of religion is that the bias towards creationism appears to be cognitively natural. Four-year-olds insist that everything has a purpose, including things like lions ('to go to the zoo') and clouds ('for raining'). When asked to explain why a bunch of rocks are pointy, adults prefer a physical explanation, while children choose functional answers, such as 'so that animals could scratch on them when they get itchy.'

Thus it seems that the four-year old view has it that 'everything has a purpose,' not just lamps and lions, but even rocks and clouds.

We take the main unresolved issue concerning 'promiscuous teleology' to be the extent to which it extends beyond children to adults, with even adults retaining the mindset of 'everything has a purpose.' While children show a strong tendency to prefer teleological explanations to mechanistic explanations across the board, adults in contemporary Western cultures tend to resist teleological accounts when considering inanimate natural things like rock piles. For instance, Kelemen (1999b: 1443-1444) asked both children and adults why a certain rock was pointy, and found that children tend to resist a mechanistic explanation in terms of bits of stuff being piled up, and instead prefer the following (bizarre) teleological explanation: 'so that animals wouldn't sit on them and smash them.' She found a strong preference for this style of teleological explanation among first and second graders, which persisted (albeit in diminished form) even among fourth graders, but was finally reversed with adults. Extending this research, Lombrozo \& Carey (2006: 180) found that 'adults accepted teleological explanations selectively,' summarizing (2006: 184):

We found that adults accept teleological explanations when two conditions obtain: (a) the function invoked in the explanation played a causal role in bringing about what is being explained and (b) the process by which the function played a causal role seems general, in the sense that it conforms to a predictable pattern.

That said, there is recent converging evidence that our childhood tendencies to teleological thinking persist through adulthood, being merely occasionally masked. Thus Lombrozo, Kelemen \& Zaitchik - investigating the recurrence of teleological explanation in patients with Alzheimer's Disease - claim (2007: 999-1000) that 'an underlying tendency to construe the world in terms of functions persists throughout life' and represents an 'explanatory default.' They (2007: 1004) conclude: 
[T] he preference for teleology is never outgrown. Rather, the preference persists throughout life, reemerging when causal beliefs that might otherwise constrain it are limited or compromised. In short, these findings provide evidence for a basic human preference to understand the world in terms of purpose. When faced with an object that supports a plausible function, humans make an immediate but defeasible inference to design, and assume a teleological explanation is warranted.

In a similar vein, Kelemen \& Rosset-speeding up adults to prevent their background beliefs from intruding - elicited explicitly teleological judgments even in scientific contexts, concluding (2009: 143): '[T] he bottom line implied by the current findings remains that, like children, college-educated adults display scientifically unwarranted teleological explanations with ease.' And perhaps the most interesting and recent results, due to Kelemen, Rottman \& Seston (2013: 1079), involved research on an expert population of physical scientists, with the finding that: 'even physical scientists, despite their extensive scientific training, routine adoption of physical-causal explanations, and anti-teleological norms, default to scientifically inaccurate teleological explanations when their cognitive resources are limited.8

\subsection{Folk teleology as unscientific}

In the psychological literature, the folk tendency to teleological explanation is generally recognized as an error, and indeed an obstacle students face in properly understanding processes such as natural selection (cf. Galli \& Meinardi 2011; Kelemen 2012). In this vein, Kelemen (2012: 68; cf. Kampourakis \& Zogza 2008; Moore et al. 2002; Gregory 2009) notes that students tend to think that a 'personified 'Mother Nature' or 'Evolution' responded to the functional needs of animals by generating or conferring the functional part with a view to preserving the animal's survival,' such as by stretching a giraffe's neck so it could reach its food. She (2012: 71) goes on to explain:

Findings suggesting that underlying beliefs about natural agency exert non-obvious influence on students' biological reasoning are potentially less surprising when considered in a broader context of research which suggests that such immanent agentive ideas influence adults' scientifically incorrect ideas about living and non-living nature more generally. For example, in contrast to their ratings of belief in God, students' ratings of the Gaia notion that 'Nature is driven to preserve living things' has been found to strongly predict undergraduates promiscuous (but often covert) tendencies to teleologically explain not only living but also non-living natural phenomena in terms of a purpose: That is, an agentive construal of nature provides a significant reason why American undergraduates find scientifically inaccurate teleological statements such as 'the sun makes light so that plants can photosynthesize' highly believable even after extensive high school and college level instruction in both the physical and life sciences.

The dismissal of teleological explanation from real science goes back at least to Bacon and the emergence of modern science from medieval Aristotelianism. As Bacon himself (1996: 365) memorably declares: 'For the inquisition of Final Causes is barren, and like a virgin consecrated to God produced nothing.' 
That said, we recognize that some philosophers - especially in response to the recurrent use of teleological notions within biology — have sought to legitimize a revised kind of 'naturalistically acceptable' teleological thinking (Cummins 1975; Millikan 1989). Indeed one reaction we have encountered to our work (in certain philosophical quarters) is to ask whether folk teleology is so wrong. So-to pick up on the terminology of Allen \& Bekoff (1995: 13-14) — one may distinguish the crude and unscientific idea of teleomentalism (or 'teleology-heavy') which regards 'the teleology of psychological intentions, goals, and purposes as the primary model for understanding teleology in biology,' from a revisionary notion of teleonaturalism ('teleology-lite') through which one may 'seek naturalistic truth conditions for teleological claims in biology that do not refer to the intentions, goals, or purposes of psychological agents' and so attempt to 'reduce teleological language to forms of description and explanation that are found in other parts of science.'

We grant - if only for the sake of the argument - that there may be some revised and scientifically legitimate teleonaturalist notions which philosophers of biology might usefully identify. Our point is simply that the folk are not teleonaturalists but full-blown teleomentalists, indulging in the heavy mentalistic projection of agency onto the entirety of nature. A classical demonstration of our adult tendency toward teleomentalism is found in an experiment due to Heider \& Simmel (1944), which involved a simple movie in which various geometrical figures - circles, squares, triangles - moved in certain systematic ways. When shown this movie, people instinctively describe the figures as if they have goals and desires. This effect persists even with unbounded figures, such as moving dots and swarms of tiny squares (Bloom \& Veres 1999). Other work suggests that this tendency to attribute agency and purpose extends to real world entities including cities, clouds, earthquakes, fire, hurricanes, the moon, mountains, plants, rain, the sun, rivers, rocks, trees, volcanoes, water, and wind (Guthrie 1993).

(In what follows we will continue to use the term 'teleology, but we are throughout referring to the illegitimate superstition of teleomentalism, and not to any potentially respectable but revisionary version of teleonaturalism that philosophers of biology might construct.)

Putting this together: Background work in psychology suggests that adults indulge in promiscuous teleological thinking. In particular, we tend to classify objects by their purposes. There is a natural connection between object categorization and the special composition question, even beyond the fact that both involve object cognition (and for that reason alone might already be thought to follow common principles). For one can think of the special composition question as asking whether $a$ thing is (that is, asking whether there is an individual $y$ that fuses the plurality of individuals $X \mathrm{~s}$ ). And there is a natural connection between how we determine what a thing is (object categorization) and how we determine whether a thing is (folk mereology). Indeed, one can plausibly equate the question of whether a thing is with the question of whether there is anything that it is (that is, one can equate existence with falling under some category or other). When the plurality of individuals collectively falls under an object category, then (and only then) should we be expected to say that the plurality has a fusion. When the plurality is for something then it is something. But when the plurality lacks a purpose-when it is for 
nothing - then it is nothing. Against this background of promiscuous teleological thinking even by adults, our hypothesis that folk mereology is teleological should be unsurprising. Our hypothesis deserves high initial credence.

\section{Folk Mereology is Teleological}

So far we have displayed a range of armchair disputes about folk mereology ( $(1)$, and documented some background psychological work on folk teleology ( 2$)$. We now describe a range of studies we conducted which support the idea that folk mereology is teleological, in the sense that people tend to intuit that a plurality of objects has a fusion partly on the basis of considering when that plurality serves a purpose.

We did face a methodological difficulty worth flagging from the start. Simply asking people the special composition question directly ('Under what conditions does some plurality of individuals $X$ s compose some one individual $y$ ?') will presumably elicit something between blank incomprehension and pure noise. Attempting to teach the relevant concepts first comes with no guarantee of success (and may generate bias, and will generate cognitive load). So instead we chose to design a variety of surveys describing various particular cases and then posing composition questions in various ways (e.g., do two mice glued together 'compose a new object'? do two ropes tied together 'create a single, unified object' or still leave one with 'two, distinct pieces of rope'?) We hoped that our results might prove robust across these diverse vignettes and probes, thereby buttressing the conclusion that we have been uniformly successful in eliciting the intended mereological concepts. Our hopes turn out to be realized. But still, we would flag the concern that some of our questions may have been read in an unintended way.

As with all empirical work, our results are subject to potential confounds and diverse interpretations, and defeasible in the light of future inquiry. We think that any open-minded person who considers all of our studies together will agree that they point overall towards a teleological view of folk mereology (especially given the psychological background of promiscuous teleological thinking). But each specific study may be questioned, and of course future results may always point in other directions, or towards a more specific form of a teleological view. Overall we hope to have provided the first but not the last word on folk mereology.

\subsection{Handshake cases}

We begin with studies we ran based on van Inwagen's (1990: 35; 57-59) famous 'handshake case.' Van Inwagen - after hypothesizing that the folk theory is something like Contact or Fastenation - asks one to imagine two people shaking hands (thereby coming into contact), or even gluing their hands together (so as to become fastened together), and then to consider whether 'a new thing' has 'at that moment come into existence.' If the folk theory were Contact or Fastenation one should think 'yes.' But if the folk theory were Nihilism, Vitalism, or Emergentism one should think: 'no, there is no sum, nothing has coming into existence.' While if the folk theory were based on Universalism one should think: "no, there always 
was a sum - nothing new has come into existence.' (If the folk theory were based on Regionalism, Serialism, or Brutalism then no prediction can be made one way or another.)

We had two goals in mind. First we wanted to test whether van Inwagen was right to predict that most people would say 'no' to the question of whether a new thing has come into existence. Secondly we wanted to see if we could flip intuitions by manipulating function. So we first tested van Inwagen's initial question, as to whether two people shaking hands and thereby coming into contact thereby create a new thing. We set up a vignette involving a handshake, and then described a disagreement between two characters-Andy and Liz - as to whether a new larger object was thereby created:

\section{Handshake}

Sally and Tom are leaders of rival political factions, and have recently decided to lay aside their differences. They have worked out all the details, signed all the official papers, and will now seal their deal with a public and historic handshake.

Later that day, Andy and Liz - who were both present for the historic handshake - have a disagreement over whether Sally and Tom created a new object when they shook hands. Andy says that simply coming into contact with someone or something is not enough to create some new thing, and claims that Sally and Tom did not create a new larger object in the moment when they shook hands.

Liz, however, disagrees. She thinks that when Sally and Tom came into contact in this case, they thereby created a new larger thing, made from Sally and Tom together.

Participants were asked the extent to which they agreed with either Andy or Liz (they were given a seven point scale with 1 marked 'Andy is right,' 4 marked 'Neither is right,' and 7 marked 'Liz is right'). Just as van Inwagen predicted, participants tended to side with Andy $(\mathrm{M}=2.48, \mathrm{SD}=1.84)$.

We then made minimal adjustments to the vignette so that the larger object formed served a purpose, by adding that a sculptor would use it as a model for a sculpture of two people shaking hands:

\section{Handshake with function}

Sally and Tom are leaders of rival political factions, and have recently decided to lay aside their differences. They have worked out all the details, signed all the official papers, and will now seal their deal with a public and historic handshake. To commemorate this historic event, a sculptor has been commissioned to sculpt the handshake. Sally and Tom together, while they are shaking hands, will be providing a model for the sculpture, which will be dubbed 'Unity.'

Later that day, Andy and Liz - who were both present for the historic handshake - have a disagreement over whether Sally and Tom created a new object when they shook hands. Andy says that simply coming into contact with someone or something is not enough to create some new thing, and 
claims that Sally and Tom did not create a new larger object in the moment when they shook hands.

Liz, however, disagrees. She thinks that when Sally and Tom came into contact in this case, they thereby created a new larger thing, made from Sally and Tom together, which served to provide a model for the sculpture.

Adding a function produced a large-sized effect on intuitions. Participants in Handshake with function tended to side with $\operatorname{Liz}(\mathrm{M}=4.86, \mathrm{SD}=1.60)$, agreeing that 'when Sally and Tom came into contact in this case, they thereby created a new larger thing, made from Sally and Tom together, which served to provide a model for the sculpture.' Here is a visual depiction of the effect of function on intuitions: ${ }^{9}$

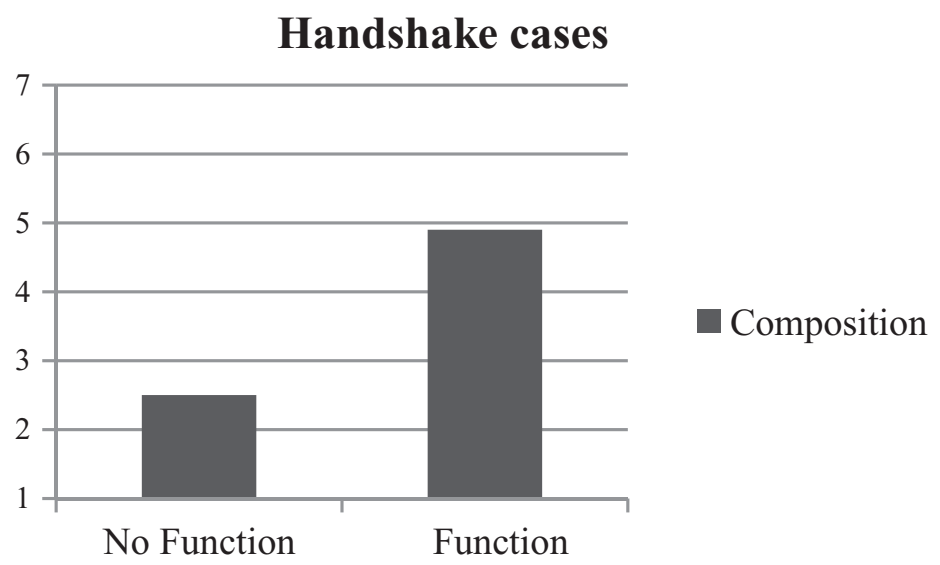

While our primary claim is just that adding a function produced a large-sized effect on intuitions, we also note that the overall effect in this case was to flip intuitions. In both Handshake and Handshake with function the responses were significantly different ( $p<.01$ in both cases) from the midpoint (4.0). So we were able to take a paradigm case in the literature of when composition fails to occur, and flip intuitions about composition by manipulating function. None of the extant answers to the special composition question $(\$ 1.1)$ predict this pattern. So, to the extent that metaphysicians are beholden to folk intuitions, we have just provided an empirically substantiated counterexample to virtually every extant account.

With these Handshake cases we see a first sign of an underlying pattern, in which intuitions about whether or not composition occurs are significantly impacted by whether or not there is a function for the candidate larger thing to serve. Our remaining studies further illustrate and clarify this pattern.

\subsection{Gollywag cases}

In another series of studies we wanted to consider an unfamiliar type of artifact ('gollywags') and consider the effect of function along multiple dimensions. We wanted to see whether there was an effect of function, and also look for any interactions with contact or with fastening. So we began with: 


\section{Gollywags with fusion}

Acme Inc. is a large research company. Two Acme Inc. researchers, Jones and Smith, have recently discovered a new thing, a 'gollywag.' Nobody has ever seen or heard of such a thing so Jones and Smith were quite surprised to stumble upon this new thing.

One day, Jones takes two gollywags and superglues them together. $\mathrm{He}$ thinks that he has created a new object.

Later that same day, Smith and Jones have a disagreement over whether the arrangement of gollywags composes a new object. Smith claims that the arrangement of gollywags does not compose a new object at all. He claims that simply supergluing some stuff together with some other stuff is not sufficient to compose a new object.

Jones, however, disagrees. He claims that simply supergluing some stuff together with some other stuff is sufficient to compose a new object. Concerning the specific case that they are considering, Jones concludes that the arrangement of gollywags does compose a new object.

We also had a Gollywags with contact case, just like Gollywags with fusion except that Jones, instead of supergluing the gollywags together, simply placed them into contact with one another.

We compared Gollywags with fusion with a case that added a function for the superglued gollywags:

\section{Gollywags with fusion with function}

Acme Inc. is a large research company. Two Acme Inc. researchers, Jones and Smith, have recently discovered a new thing, a 'gollywag.' Nobody has ever seen or heard of such a thing so Jones and Smith were quite surprised to stumble upon this new thing.

Jones is a very hard worker and spends long hours in his office, spending most of his time sitting at his desk. On most days, his back becomes very sore from sitting for so long at his desk.

One day, Jones is working at his desk as he usually does. His back starts to become very sore from sitting for so long. He decides that he will take two of the gollywags and superglue them together, making what he thinks to be a new object, what he calls the 'Gollywag-Supporter.'

He places the Gollywag-Supporter on his desk chair and continues to work. At the end of the day, his back is not sore at all.

The next day, Smith and Jones have a disagreement over whether the arrangement of gollywags composes a new object. Smith claims that the arrangement of gollywags does not compose a new object at all. He claims that simply super-gluing some stuff together with some other stuff is not sufficient to compose a new object.

Jones, however, disagrees. He claims that simply supergluing some stuff together with some other stuff is sufficient to compose a new object. Concerning the specific case that they are considering, Jones concludes that the 
arrangement of gollywags does compose a new object, namely a GollywagSupporter.

We also had a Gollywags with contact with function case, just like Gollywags with fusion and function except that Jones, instead of supergluing the gollywags together, simply placed them into contact with one another.

We found, in line with our Handshake cases (\$3.1) but not in line with any of the extant answers to the special composition question, that function continued to have a significant (in this case medium-sized) impact on judgments about composition. We also found no effect of contact versus fusion (thus undermining the idea that causal joining plays a significant role in our intuitions), and no interaction between the presence or absence of function and the presence of contact or fusion, as may be visualized in: ${ }^{10}$

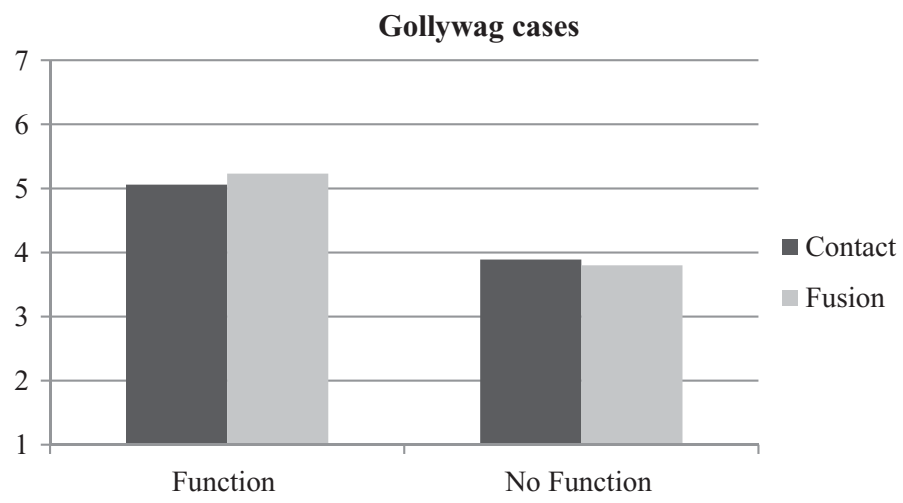

With the Gollywag cases we thus see a continuation of the underlying pattern of teleologically influenced intuitions. Further, we see no evidence that other factors, in particular the kind of causal connectedness or joining that fastening adds to contact, play any role in folk intuitions about when composition occurs, either alone or in interaction with function.

We also note that this is the one case of ours in which we did not see a flip in intuitions, insofar as we did not detect a statistically significant difference between responses in the No Function cases and the midpoint (marked as 'Neither is right'). The presence or absence of function is continuing to produce an effect on intuitions, as per our primary claim. Moreover, responses in the Function cases were significantly above midpoint (in the direction of 'Jones is right'). But our data in this one case is consistent with the thought that people tend to be neutral, undecided, or just confused about what to say in some cases when no function is specified.

\subsection{Mouse cases}

With our Gollywag cases we looked at composition judgments for artifacts. We wanted to see if the same pattern of intuitions extended for biological organisms, and we also wanted to explore potential effects of familiarity, and of having a name 
to label the larger thing. So we began with familiar organisms - mice-and looked at the effect of function between:

\section{Mice with fusion}

Acme Inc. is a large research company. Two Acme Inc. researchers, Jones and Smith, are experimenting with mice.

One day, Jones takes two mice and superglues them together. He thinks that he has created a new object.

Later that same day, Smith and Jones, have a disagreement over whether the arrangement of mice composes a new object. Smith claims that the arrangement of mice does not compose a new object at all. He claims that simply supergluing some together with some other stuff is not sufficient to compose a new object.

Jones, however, disagrees. He claims that simply supergluing some stuff together with some other stuff is sufficient to compose a new object. Concerning the specific case that they are considering, Jones concludes that the arrangement of mice does compose a new object.

And:

\section{Mice with fusion and function}

Acme Inc. is a large research company. Two Acme Inc. researchers, Jones and Smith, are experimenting with mice.

The FBI has commissioned Jones and Smith and given them the task of determining whether mice can be used to sniff out explosives. Typically, dogs are used to sniff out explosives but in some cases dogs are way too large to enter certain types of spaces. So, the FBI wants to see if a smaller creature can sniff out explosives with the same degree of accuracy as a dog.

For many months, Jones and Smith have been running the mice through various types of mazes, trying to determine how quickly and accurately the mice can find explosives. But they are having little luck: the mice are much slower and much less accurate than dogs in finding explosives.

One day, Jones takes two mice and superglues them together. He runs a wide range of experiments and finds that when the two mice are superglued together they are both very fast and highly accurate at detecting explosives. As a matter of fact, when two mice are superglued together, they are both faster and more accurate than dogs at detecting explosives. Jones thus thinks that he has created a new object, the 'Mini-Bomb Detector.'

The next day, Smith and Jones have a disagreement over whether the arrangement of mice composes a new object. Smith claims that the arrangement of mice does not compose a new object at all. He claims that simply supergluing some stuff together with some other stuff is not sufficient to compose a new object.

Jones, however, disagrees. He claims that simply supergluing some stuff together with some other stuff is sufficient to compose a new object. Concerning the specific case that they are considering, Jones concludes that the 
arrangement of mice does compose a new object, namely a Mini-Bomb Detector.

Alongside all of this, we also wanted to explore potential effects of familiarity, and of having a name to label the thing. So we looked at counterpart cases in which we replaced the mice with an unfamiliar sort of organism, for which we again used 'gollywag.' And we also looked at further counterpart cases in which we deleted the label 'mini-bomb detector,' to check if the presence of the label was influencing intuitions. ${ }^{11}$

Our results confirmed and extended the results of our Handshake and Gollywag (artifact) cases (\$§3.1-3.2). We continued to find a significant medium-sized effect of function on judgments about composition, and we found no other effects (either alone or in interaction). Whether the organisms were familiar (mice) or unfamiliar (gollywags), and whether they were jointly labeled (a 'mini-bomb detector') or left unlabeled made no detectable difference to intuitions. All that seemed to drive intuitions was whether or not the candidate larger thing served a purpose. Since only function had any effect on composition, we've aggregated responses across all remaining conditions in the following visualization: ${ }^{12}$

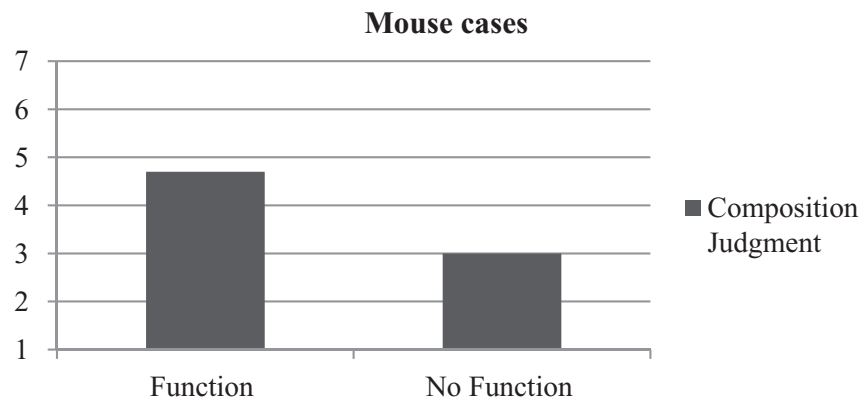

With the Mouse cases we thus see a continuation of the underlying pattern of teleologically influenced intuitions. We moreover see that the effect of function was to again flip intuitions (i.e., responses in both the Function and No Function cases were significantly different from the midpoint). Further, we see no evidence that other factors including familiarity and labeling play any role in folk intuitions about when composition occurs.

\subsection{Avalanche cases}

Our cases so far have been limited in two main respects. First, we have mainly focused on artifacts and organisms, for which it is well established (even given just 'selective teleology': \$2.1) that people tend to think teleologically. We have not yet looked at natural non-biological things such as rocks (where one needs 'promiscious telelology' [\$2.2] to predict an effect). Secondly, we have only looked at larger things that are at least spatiotemporally connected, and sometimes even fastened together. We have not yet looked at scattered things, so left open whether there still might be some effect of scattering versus contact, or some interaction between scattering and function. So we turned to cases involving a scattered collection of rocks, to see if 
attributing a function (having the rocks designed to serve as a rock garden) would have an effect, and to continue checking for effects of labeling. We also wanted to start getting 'inside' the notion of a function by comparing the case in which a thing was designed from the start to serve a function, with the case in which a thing has already come to be (seemingly by accident) and is then accorded a function after the fact.

So in order to look at scattered collections of rocks, we began with:

Avalanche (base)

Jones lives on the side of a mountain. He has just been awoken by a series of loud crashes from a small avalanche on the mountain. Jones wakes up and looks outside, and sees a bunch of rocks strewn across his lawn from the avalanche.

We wanted to vary whether or not the rocks were given a label, whether or not they were accorded a function as a rock garden, and whether or not Jones then rearranged the rocks so that they were actually designed to serve that function. This resulted in six different extensions of Avalanche (base):

Avalanche

[Avalanche (base) plus] Though he is surprised, he just goes back to bed.

Avalanche with label

[Avalanche (base) plus] He thinks to himself, 'Looks like I have mountain man's rock garden!' He goes on thinking to himself, 'What a useless messlooks like I'll have to clean all this up in the morning.'

\section{Avalanche with accorded function}

[Avalanche (base) plus] Even though avalanches are usually quite annoying for Jones, he decides at that moment that the rocks are actually strewn across his lawn in such a way that they will make his front lawn beautiful. He thus thinks that the arrangement of rocks from the avalanche compose a new object, namely an object that would make his front lawn beautiful.

\section{Avalanche with accorded function and label}

[Avalanche (base) plus] Even though avalanches are usually quite annoying for Jones, he decides at that moment that the rocks are actually strewn across his lawn in such a way that they will do perfectly for a beautiful rock garden. He thus thinks that the arrangement of rocks from the avalanche compose a new object, namely a rock garden.

\section{Avalanche with designed function}

[Avalanche (base) plus] Even though avalanches are usually quite annoying for Jones, he decides that in the morning he'll use them to make his front lawn beautiful.

The next day, he arranges all of the rocks in such a way that he thinks he has created something that makes his front lawn beautiful. He thus thinks that the arrangement of rocks compose a new object, namely an object that makes his front lawn beautiful. 


\section{Avalanche with designed function and label}

[Avalanche (base) plus] Even though avalanches are usually quite annoying for Jones, he decides that in the morning he'll use them to make a rock garden.

The next day, he arranges all of the rocks in such a way that he thinks he has created a rock garden. He thus thinks that the arrangement of rocks compose a new object, namely a rock garden.

Our results on these six cases confirmed and extended our previous results. We continued to find a significant (now large-sized) effect of function on judgments about composition, and we found no effect of naming and no interaction between naming and function. We also found a significant difference between accorded function and designed function, as may overall be visualized in: ${ }^{13}$

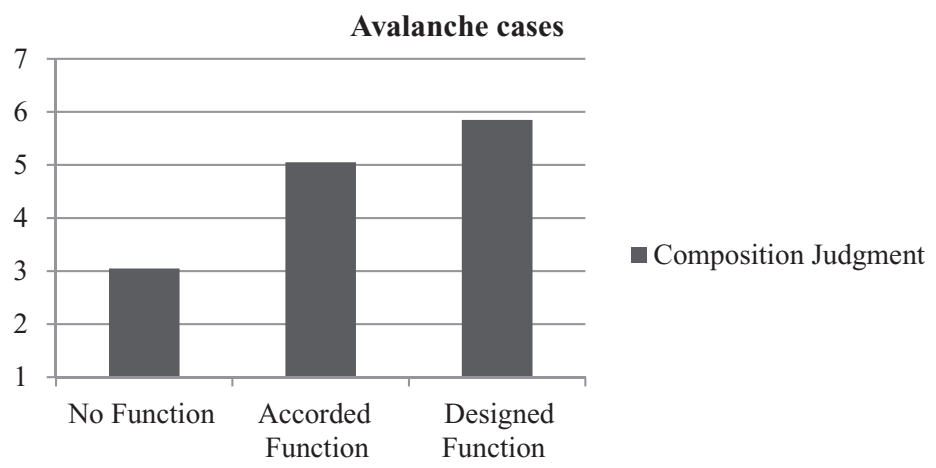

Thus with the Avalanche cases we see a continuation of the underlying pattern of teleologically influenced intuitions, extended even to cases with scattered rocks. And we start to see inside this pattern, by seeing that merely according a function is already sufficient to influence intuitions, but that having the thing designed all along to serve the function produces an even stronger effect. Putting this all together, and considering the totality of our studies, it seems that the folk operate with a restricted and teleologically-laden view of when composition occurs. Through a range of very different cases we find a significant effect of function on judgments of when composition occurs, as per our main thesis. Indeed, in all cases save that of our Gollywag cases (\$3.2) we saw an effect that we would describe as 'flipping intuitions,' from significantly below to significantly above the midpoint.

\subsection{Rope cases}

So far we have only looked at cases in which the object succeeds at serving its purpose. Indeed the existing psychological literature on object categorization focuses almost exclusively on such cases, in which the object works as intended. We also wanted to consider cases in which something fails to serve the purpose it was designed for (so as to get further 'inside' our notion of function), as well as take the opportunity to vary our probe further. So we worked with the following vignettes: 


\section{Ropes failure}

Jones has an old, rusty water heater lying in his backyard. He thinks the water heater is ugly and so decides to move it out of his yard. So he ties a piece of rope around the water heater and pulls on it. But it does not move at all. Jones then thinks to himself, 'The rope must be too short. I need something longer to get more leverage.' He thus grabs another piece of rope and ties it in a knot around the other piece of rope that is already around the water heater. Jones then pulls on it but still the water heater does not move at all.

\section{Ropes success}

Jones has an old, rusty water heater lying in his backyard. He thinks the water heater is ugly and so decides to move it out of his yard. So he ties a piece of rope around the water heater and pulls on it. But it does not move at all. Jones then thinks to himself, 'The rope must be too short. I need something longer to get more leverage.' He thus grabs another piece of rope and ties it in a knot around the other piece of rope that is already around the water heater. Jones then pulls on it and is easily able to drag the water heater out of his yard.

We asked people whether they thought that Jones 'created a single, unified object' or whether 'When Jones tied the pieces of rope together, he did not create a single, unified object out of the rope. Rather, he simply had two, distinct pieces of rope.'

We found that success matters in a significant small-sized way to people's intuitions. In Ropes failure only $36 \%$ of our participants chose the option of 'a single, unified object,' while in Ropes success $63 \%$ of our participants chose the option of 'a single, unified object.' Graphically: ${ }^{14}$

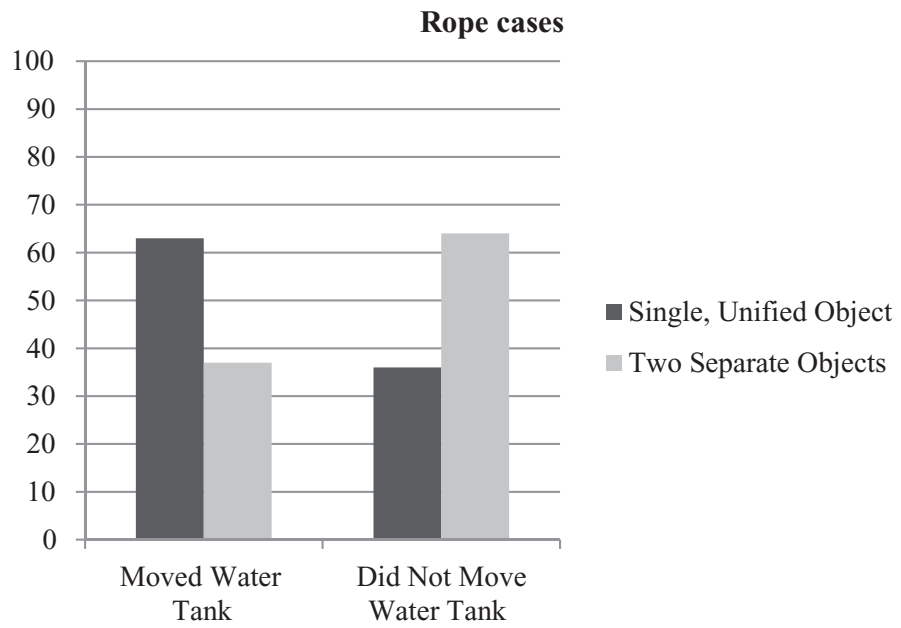

We thus see further confirmation for the view that the folk operate with a restricted and teleologically-laden view of when composition occurs, alongside further and new clarification of the folk notion of function. Comparing these results with 
our earlier results on Avalanche cases (\$3.4), we can contrast two different dimensions along which a thing might be said to have a purpose (in the sense relevant to the folk). First, the thing might be originally designed to serve a given function, or it might merely be accorded a function after the fact. Secondly, the thing might succeed in serving whatever function it was either designed for or accorded, or it might fail to serve this function. It seems (from the Avalanche cases) that accordance versus design is not crucial for serving a purpose (though design seems to bolster intuitions somewhat). And it seems (from the Rope cases) that success tends to be required. ${ }^{15,16}$

\subsection{Restricted composition or restricted domain?}

The friend of Universalism who (like Lewis and Thomasson) thinks that her theory does not conflict with folk intuitions has one more trick up her sleeve. Instead of saying that the folk operate with a restricted and teleologically-laden view of when composition occurs, she might say that the folk operate with an unrestricted view of when composition occurs, coupled with a teleological restriction of the domain of quantification. That is, she can treat the folk as upholding Universalism alongside:

Teleologically Restricted Domain: In normal contexts, quantifiers are restricted to things that have a purpose

There is something to be said for this move, insofar as it will be vague whether something has a purpose, and insofar as Teleologically Restricted Domain relocates this vagueness from the metaphysics to the semantics (where vagueness most plausibly belongs). If this move could be shown to work, we would regard this as a very interesting result in its own right!

With this trick in mind, we returned to our Handshake cases $(\$ 3.1)$ and had one of the characters (Andy) speak explicitly on behalf of Universalism, saying the sort of things one might reasonably say to ensure that the domain of quantification is sufficiently open. This yielded:

\section{Handshake without restrictions}

Sally and Tom are leaders of rival political factions, and have recently decided to lay aside their differences. They have worked out all the details, signed all the official papers, and will now seal their deal with a public and historic handshake.

Later that day, Andy and Liz - who were both present for the historic handshake - have a disagreement over whether Sally and Tom created a new object when they shook hands.

Andy says that Sally and Tom did compose a single object. Indeed, he says that Sally and Tom always made a single, larger object, not just during the handshake, but before and after too. He says that in addition to the two people, Sally and Tom, there is, was, and will also be this larger object made of the two of them together. He says, 'This larger object, which I will call 'the Sally-Tom hybrid' has two parts: a Sally part, and a Tom part. It weighs just as much as Sally and Tom put together. Before the handshake, its two parts 
were scattered, during the handshake its two parts came into contact briefly, and after the handshake its two parts scattered. I know that we have no usual name for this larger object, and I know that it is not the sort of thing we usually chat about, but it is there all the same.'

Liz, however, disagrees. She says that, both before Sally and Tom shook hands, during their handshake, and after, there were just two people present. There was never any third, larger object made from Sally and Tom together, either before, during, or after the handshake. She clarifies: 'There is no such thing of any sort as your alleged 'Sally-Tom hybrid.' It's not just that we don't usually chat about this thing. There is no such thing.'

Despite Andy's explicit description of the sort of fusion he has in mind, and despite his explicit moves to open up the quantifiers, our participants still tended to agree with Liz that 'It's not just that we don't usually chat about this thing. There is no such thing. ${ }^{17}$

Accordingly we see little prospect in sustaining Lewis's idea that our hesitation to accept the existence of arbitrary sums is merely due to contextual domain restrictions, and little prospect in sustaining Thomasson's (2007: 184) speculation that if 'we explained to 'normal' people' a term for some arbitrary sum, and then asked them if there is such a thing, they 'would certainly accept that there is.' Instead we find empirical substantiation for Korman's (2008) skepticism that folk intuitions can be explained by Universalism plus domain restrictions. Of course it is possible that - despite Andy's explicit description of the sort of sum he has in mind, and his explicit moves to open up the quantifiers - he still failed to open up the quantifiers sufficiently. But pending real evidence for this it must be considered doubtful. (Compare: In paradigm cases of quantifier domain restriction such as when one says 'All the beer is in the fridge,' it is very easy for an interlocutor to open up the quantifiers such as by saying 'If we need more beer there is more at the grocery story on the corner.') And given the background psychological evidence that we are natural teleologists $(\$ 2)$ this view must be considered more doubtful still. It's not just that we usually choose to focus on things with a purpose; it's rather that we naturally equate being a thing with having a purpose.

\subsection{Teleologically restricted composition}

Putting this all together, and considering the totality of our studies in light of the background psychological evidence about the role of teleology in folk metaphysics, we find empirical support for the idea that teleology plays a significant role in folk judgments about composition:

Teleologically Restricted Composition: Composition occurs in restricted circumstances, in which the question of whether the plurality has a purpose plays a significant role

We would emphasize that we are offering Teleologically Restricted Composition as an account of the folk theory, and not as a metaphysical claim. We sometimes hear: 'Surely the folk accept that there are composites like rocks and clouds which 
serve no purpose.' But it should not be presumed that the folk think that rocks and clouds serve no purpose. Indeed, as we have already noted (\$2.2), the folk tend to regard everything as having a purpose, including every rock and cloud ('clouds are for rain').

We would further emphasize that Teleologically Restricted Composition is not an exhaustive claim about what factors drive folk intuitions. We claim that teleology is one factor driving folk intuitions, not that it is the only such factor. That would require the strong claim:

Purely Teleologically Restricted Composition: Composition occurs if and only if the plurality has a purpose

We leave open whether Purely Teleologically Restricted Composition holds, and will only operate with the more modest claim that Teleologically Restricted Composition holds.

To establish Purely Teleologically Restricted Composition would be to prove the negative existential that no other factors play a role in the folk theory, which obviously we cannot prove. Indeed there may be good empirical reason to doubt Purely Teleologically Restricted Composition, stemming from the role that gestalt principles play in visual cognition. ${ }^{18}$ As Goldman (1993: 108) usefully summarizes:

We do not readily consider something as a physical body if it lacks cohesion (a pile of leaves), lacks bounds (a drop of water in a pool), or lacks continuity (a row of flashing lights). These may be considered collections of objects or parts of objects, but they are not unitary and independent objects for us.

Indeed it may be the case that the visual system operates with an implicit 'theory' of composition that differs from that used by other cognitive systems. (Though we would expect any such influence to be operative only when the plurality is visually presented, and so probably not triggered in philosophical intuitions given the usual narrative presentation of cases.)

That said, our studies did not turn up any effect of gestalt factors like contact or fusion (\$3.2), or of other factors like familiarity or labeling (\$\$3.3-3.4) or quantifier restrictions (\$3.6). While inferences from a null result on a particular study to a 'no effect' conclusion are notoriously fraught (though see Machery 2012), these null results at least provide some support for the idea that contact, fusion, familiarity, labeling, and quantifier restrictions are not playing a significant role in folk intuitions about when composition occurs, at least in narrative presentations of cases. This is especially relevant since philosophers have speculated that contact and/or fusion may be the main drivers of folk intuition (\$§1.2-1.3). Thus our studies do at least provide some support for the idea that the most plausible additional factors other than teleology are not in fact driving folk intuitions, at least for the usual narratively presented cases. (Perhaps contact, fusion, and other gestalt-related factors might have played a role in judgments about visual stimuli.)

In any case, our ultimate purpose is to debunk folk intuitions on grounds that they are laden with primitive teleological thinking ( $\$ 4.2)$, and for that purpose Teleologically Restricted Composition is sufficient. So in that sense the empirical 
question of whether there are further factors driving folk mereology-interesting as it may be-does not make a difference to our ultimate conclusion. Accordingly we will leave the prospect of further factors aside in what remains, as an invitation for follow-up empirical work. (Though we briefly return to the issue in $\$ 4.1$ when we consider the prospects for a 'cleaned up' folk theory.)

\section{Implications}

We began by documenting various answers to the special composition question and the charges of 'mereological madness' that have played a major role in the metaphysical debate $(\S 1)$. We then offered an empirically driven case for regarding folk mereology as teleological (\$\$2-3). We conclude by discussing some of the metaphysical and methodological implications of our research.

\subsection{Metaphysical implications}

If we are right that folk mereology is teleological, what follows for the special composition question? That is, what if any morals should the metaphysician draw from our discussion? First and foremost, we hope to have made an empirically substantiated case that answers to the special composition question should not be beholden to folk intuitions. Accordingly we claim to have liberated the prescriptive metaphysician from the various charges of 'mereological madness' in the literature. Whatever problems Universalism or Nihilism or any of the other extant views about composition might have, failure to fit folk intuitions is not among them. (Not because these views fit folk intuitions, but because folk intuitions in this domain are tied into a benighted teleological view of nature.)

Folk mereology looks to us in many ways akin to folk physics. Both involve fascinating conceptual machinery worthy of extended psychological study, but neither can make any serious claim to fitting reality. Objecting to a philosophical theory of mereology on grounds that it violates folk intuitions about composition looks to us roughly on par with objecting to Newtonian mechanics on grounds that it violates folk intuitions about persistent curvilinear motion (Kaiser, McCloskey, and Proffitt 1986). In both cases the theories do conflict with folk intuitions, but the folk intuitions deserve dismissal. ${ }^{19}$

We imagine three likely follow-up reactions to our claim that folk mereology is teleological. ${ }^{20}$ One sort of follow-up reaction - which certain sorts of opponents of experimental philosophy might be drawn to - would be to say 'let us then ignore the ignorant folk and turn to the real experts, namely the metaphysicians.' We do not think it is obvious that the metaphysicians have earned the mantle of 'experts' on the matter. But setting that aside, while we do not have empirical evidence as to the distribution of views among metaphysicians, it certainly seems from the current literature as if there is little agreement among the metaphysicians, not just with respect to theory but with respect to intuitions reported. We see intuitions reported swinging all the way from Universalism to Nihilism and stopping at many places between (\$1.2). The folk may be benighted, but the 'experts' seem divided. 
A second sort of follow-up reaction - which some partisans in the metaphysical dispute might be drawn to-would be to appeal to 'corrected' intuitions in a revised argument for mereological sanity. Perhaps if we could just wipe the teleological muck off from the folk theory we would find clean intuitions by which to judge theories. We are skeptical, in part because we can imagine different partisans in the metaphysical dispute spinning this move in different ways. We can imagine the friend of Universalism saying: 'The folk only ever reject composition when they think the result has no purpose; wipe off the teleological muck and the folk would no longer ever reject composition.' But we can equally imagine the friend of Nihilism saying: 'The folk only ever accept composition when they think the result has a purpose; wipe off the teleological muck and the folk would no longer ever accept composition.' And we can just as equally imagine partisans of various restrictive views saying: 'The folk clearly hold a restricted theory and we should try to honor that commitment; wipe off the teleological muck and the folk would only need a more respectable restriction.' The folk concept can be cleaned up in many ways. We doubt there is a determinate fact as to 'the' corrected folk theory.

(It may be that further empirical work will reveal that the folk operate with a plurality of factors, or perhaps even recruit different factors for different tasks [§3.7]. It may then be possible to consider a more determinate cleaned-up folk theory operating with just those other factors. But for present purposes we can only say that we have not uncovered any positive evidence for other factors [including factors such as contact and fusion which had been thought operative], and we cannot guess what further factors could potentially be involved. Overall we suggest that those attracted to correcting the folk theory do the empirical work to determine if there are any residual and respectable factors remaining in the folk theory, which might still be retained. We would welcome such follow-up empirical work.)

A third sort of follow-up reaction - which some skeptics about prescriptive metaphysics might be drawn to-would be to say that the special composition question has been revealed to be hopeless, in that we lack the epistemic wherewithal to select the right answer. ${ }^{21}$ As Rosen \& Dorr (2002: 154-156) clarify, each proposal is analytically consistent, and all the proposals seem to be empirically equivalent. If intuitions cannot help either, what remains? (We suspect that this is why intuitions loom so large in the current debate: $§ 1.1$.

Perhaps the skeptic is right. Though we think that there are still virtues of simplicity, elegance, and coherence with wider theory in play that may still help favor certain approaches. Overall we suspect that liberating the special composition question from folk intuitions helps tilt the overall balance somewhat in favor of the elegant but 'radical' extreme views of Universalism and Nihilism, over the more complex but 'conservative' intermediate positions. But this is a matter that obviously falls beyond the scope of the current discussion.

\subsection{Methodological implications}

We take our results to support a targeted debunking of folk intuitions about when composition occurs. Epistemically speaking, we hold that any line of argument that is premised on folk intuitions about composition suffers from an undermining 
defeater (cf. Pollock 1987). Just as the force of testimony is undermined if it is discovered that the testimony is based on a deluded view on the topic, so the force of intuition is undermined it is discovered that the intuitions are based on a hopeless theory of the topic. (As is standard with defeaters, there can also be reinstaters. For instance the deluded views of the testifier may happen by luck to agree with reasoned views in the case at hand. But any such reinstatement must be shown.)

In other words, we want to say that there is a debunking explanation for folk intuitions about when composition occurs. ${ }^{22}$ Imagine that it is discovered that we intuit that something is alive when we think the thing has a spirit. Our intuitions about when something is alive would thereby be debunked, and should be accorded no weight in disputes about biological classification. Likewise if it is discovered that we intuit that some things fuse when we think they have a collective purpose, our intuitions would thereby be equally debunked, and would thereby equally deserve no weight in disputes about mereological composition. (As is standard with debunking explanations, there can be restorers. For instance it might be found that the 'spirited' view of life is connected with a tendency to attribute being spirited on the basis of reliable indicators of life, such as self-movement. But any such restoration must be shown.)

There are of course difficult background issues about where to draw the line with debunking explanations. On the one hand, if we demand that our folk theories be perfect to be trusted, then we will be left with a blanket skepticism about intuitions. Perhaps such a skepticism is defensible; we only do not wish to premise our argument on such a radical view. On the other hand, if we allow our folk theories to be terrible and still trust them, then we are left with a naive credulity about intuitions. Theorizing about this issue is obviously beyond the scope of the current discussion. But for present purposes our claim is that there are clear cases of undermining defeaters and debunking explanations (such as our hypothetical spiritual folk biology), and that teleological folk mereology is one such clear case.

We note that our attempt at debunking is targeted, insofar as we have tried to identify a very specific flaw in our folk worldview. Korman (2009: 244) raises the general worry that attempts at debunking folk intuitions may either be globally self-defeating, undermining all reasoning whatsoever, or locally self-defeating, undermining specific premises in the very argument used for debunking. Insofar as our reasoning targets specific features of our naïve view of the natural world, it does not undermine reasoning generally, nor do we ever appeal to naive teleological reasoning ourselves. In this way we hope to have illustrated a stable and targeted strategy for debunking folk intuitions.

To summarize: Many metaphysicians have wanted a view of mereological composition that fits with folk intuitions, and have charged leading views with failing to do so, while failing themselves to agree as to what the folk intuit or why. So we have tried to put the tools of experimental philosophy to constructive use to break this impasse. We have found something that, though unconsidered by any of the metaphysicians, coheres very well with recent psychological work: folk intuitions are based on a crude teleologically-laden conception of when composition occurs. The folk tend to connect composition to purpose. And we have suggested, in 


\section{conclusion, that this finding should lead us to liberate the metaphysics of composi- tion from any demand of fitting with folk intuitions. Folk mereology is teleological, and hence unenlightened. ${ }^{23}$}

\section{Notes}

${ }^{1}$ There is debate as to whether there is a single category-neutral relation of composition, or perhaps a range of analogous category-restricted relations (cf. van Inwagen 1990: 18-20). On the one hand we do use 'part' for relations not just among material objects, but also among spatiotemporal regions, events ('the inning is part of the baseball game'), and abstracta ('the chapter is part of the book,' 'the hypotenuse is part of the triangle'). On the other hand it is not obvious that all of these are literal applications of one and the same neutral notion. We also use temporal notions in describing abstracta ('the sequence converges rapidly'), but no one takes this to indicate that we need a single neutral account of time that equally covers abstracta.

${ }^{2}$ Serialism and Brutalism differ from the preceding seven views on the table over whether a general and informative answer to the special composition question can be given, though this difference plays no role in our discussion.

${ }^{3}$ For the interested reader: On Nihilism, Bennett (2009: 44), Schaffer (2009: 358), and Kriegel (2011: 198) are among the many who charge that it violates commonsense, though Rosen \& Dorr (2002: 158) claim that commonsense is on reflection neutral. On Contact and Fastening, van Inwagen (1990: 34) and Markosian (1998: 223) claim these views to be close to commonsensical, but van Inwagen (1990: 35; 57-59; cf. Markosian 1998: 224) offers an intuitive counterexample (his handshake case: §3.1). On Vitalism, Hirsch (2002: 67) says that it is hard 'to keep a polite straight face' at the idea that there are apple trees but no apples, while van Inwagen (1990: 103) claims no conflict with 'Universal Belief.'

${ }^{4}$ For instance, Lewis (1986: 211) claims that the folk focus on qualities, locations, and causal connections, Hoffman and Rosenkrantz's (1997: 73) speak of a 'key commonsense intuition' in terms of the parts being joined together so as to be pushed or pulled together, and Simons (1987: 303) speaks of a kind of intuitive 'integrity of internal connectedness' of wholes which he understands in terms of ontological dependence.

${ }^{5}$ The literature is vast and of course there are exceptions to the general rule. For instance, Rea (1998: 354) speaks of having a possible purpose as sufficient for composition. And-as we discovered after writing this paper-Bowers (manuscript) defends a teleological view of composition more or less exactly in line with the view we attribute to the folk.

${ }^{6}$ It is probably impossible to say anything about Aristotle without incurring scholarly controversy. For present purposes we only claim 'broadly Aristotelian' roots. For a detailed discussion of Aristotle on mereology, see Koslicki 2008 (ch. 6.).

${ }^{7}$ See the response pieces to Atran (1998) for a useful overview of the main positions.

${ }^{8}$ It may be useful to invoke the image of a 'dual processing system,' on which the human mind is viewed as having both 'Type 1' automated, encapsulated, and intuitive animalistic systems, as well as 'Type 2' deliberative, general, and reflective systems layered over the Type 1 systems by evolution. Then we might say that teleological thinking is the product of Type 1 systems. To the extent that collegeeducated adults can sometimes avoid teleological thinking, it is only through the effortful employment of a trained Type 2 cognitive mechanism. In this vein Kelemen, Rottman \& Seston (2013: 1075) characterize their view as 'akin to dual-processing models that characterize early developing intuitions as heuristics that can be increasingly overridden later in development by effortful processing, but which can nevertheless persistently reemerge in cases when intuitions are favored or forced.'

${ }^{9}$ A total of 62 participants were recruited through Amazon's Mechanical Turk and randomly assigned to either Handshake or Handshake with function. After reading the case and indicating who they agreed with (Liz or Andy), participants were then taken to a separate page where they answered three comprehension questions:

1. Sally and Tom are leaders of rival political factions (yes/no)

2. Andy thinks that the handshake did not create a larger object (yes/no)

3. Liz thinks that the handshake did create a larger object (yes/no) 
Four participants missed one or more comprehension questions in Handshake while three participants missed one or more comprehension questions in Handshake with function. After excluding these participants, a total of 55 responses were analyzed using a one-way analysis of variance. We found that whether or not the larger object served a purpose (No Function: $\mathrm{M}=2.48, \mathrm{SD}=1.84$; Function: $\mathrm{M}=4.86$, $\mathrm{SD}=1.60)$ produced a statistically significant large-sized effect of people's composition judgments $\mathrm{F}(1$, $55)=26.824, p<.001, \eta p^{2}=.383$. Moreover, responses in both the No Function and Function cases were significantly different from the midpoint: No Function $\mathrm{t}(28)=-4.43, \mathrm{p}<.001$; Function, $\mathrm{t}(27)=2.82$, $\mathrm{p}<.01$.

Throughout we report effect sizes. For the studies (such as the Handshake cases) which included a scaled, dependent variable, we report effect sizes using partial Eta squared $\left(\eta p^{2}\right)$, which is the amount of variance in the dependent variable explained by a given independent variable plus its associated error variance. For studies with a binary dependent variable, we report effect sizes using Cramer's V, which is a nonparametric correlation coefficient that indicates the strength of the relationship between nominal variables. Both of these measures deliver a value between 0 and 1. We follow Ellis (2010) for interpreting the magnitude of the effect sizes. So for Cramer's V we interpret values greater than or equal to .5 as large, greater than or equal to .3 but less than .5 as medium, and greater than or equal to .1 but less than .3 as small. And for $\eta p^{2}$ we interpret values greater than or equal to .14 as large, greater than or equal to .06 but less than .14 as medium, and greater than or equal to .01 but less than .06 as small.

${ }^{10} 121$ participants were recruited from Amazon's Mechanical Turk, and randomly assigned to one of four conditions. After reading the case, participants were asked the extent to which they agreed with either Jones or Smith (they were given a seven point scale with 1 marked 'Smith is right,' 4 marked 'Neither is right,' and 7 marked 'Jones is right'). Participants were then given, on a separate page, three comprehension questions:

1. Jones and Smith were talking about what is required to create a new thing (yes/no)

2. When Jones said that supergluing two things together [putting two things into contact] is sufficient for creating a new thing, what he was saying was that if you superglue any two things together [put any two things into contact with one another], then that is enough to create a new thing (yes/no)

3. Suppose someone said that supergluing two things together [putting two things into contact] is sufficient for creating a new thing. If that person were to take a wheel and a piece of metal and then superglue them together [put them into contact with one another], then that person would think that a new thing was created (yes/no)

Six people were excluded from the data analysis for failing at least one of the comprehension questions. Analyzing the remaining 115 responses using a two-way analysis of variance, we found that whether the gollywags had a function or not produced a statistically significant medium-sized effect on people's judgments $\mathrm{F}(1,115)=12.492, \mathrm{p}=.001, \eta \mathrm{p}^{2}=.101$, with people tending to disagree that the gollywags composed an object when the gollywags had no function $(\mathrm{M}=3.85, \mathrm{SD}=1.94)$ and agreeing that the gollywags composed an object when they had a function $(\mathrm{M}=5.15, \mathrm{SD}=1.99)$. There was no effect of the relation type (contact, fusion) on people's composition judgments $F(1,115)=.016$, $\mathrm{p}=.901$ and there was no interaction between function and relation type on people's judgments $\mathrm{F}(1$, $115)=.329, p=.567$. Since there was only an effect of function, we looked at whether responses in the No Function and Function cases differed from the midpoint. We found that responses in the Function cases were significantly different from the midpoint, $\mathrm{t}(60)=4.48, \mathrm{p}<.001$ but that responses in the No Function cases were not, $\mathrm{t}(55)=-.557, \mathrm{p}=.580$.

${ }^{11}$ We thus had a 2 (Function: Yes, No) x 2 (Label: Yes, No) x 2 (Familiarity: Gollywag, Mouse) design, resulting in a total of eight conditions.

${ }^{12} 212$ participants were recruited from Amazon's Mechanical Turk, and randomly assigned to one of eight conditions. After reading the case, participants were asked the extent to which they agreed with either Smith or Jones (they were given a seven point scale with 1 marked 'Smith is right,' 4 marked 'Neither is right,' and 7 marked 'Jones is right'). Participants were then given, on a separate page, five comprehension questions:

1. Jones said that supergluing the [gollywags/mice] together did create a new object (yes/no)

2. Smith said that supergluing the [gollywags/mice] together did not create a new object (yes/no) 
3. Suppose someone said that supergluing two things together is sufficient for creating a new thing. If that person were to take a wheel and a piece of metal and then superglue them together, then that person would think that a new thing was created (yes/no)

4. When Jones said that supergluing two things together is sufficient for creating a new thing, what he was saying was that if you superglue any two things together, then that is enough to create a new thing (yes/no)

5. Jones and Smith were talking about what is required to create a new thing (yes/no)

Eight people were excluded from the data analysis for failing at least one of the comprehension questions. Analyzing the remaining 204 responses using a three-way analysis of variance, we found that having a function or not produced a statistically significant medium-sized effect on whether people judged that the arrangement of mice or gollywags composed a new object $\mathrm{F}(1,204)=30.115, \mathrm{p}<.001$, $\eta \mathrm{p}^{2}=.133$ : when the mice or gollywags served a function people tended to judge that they composed a new object $(\mathrm{M}=4.70, \mathrm{SD}=1.15)$ but when they did not serve a function people tended to deny this $(\mathrm{M}=3.00, \mathrm{SD}=1.73)$. Neither Label $\mathrm{F}(1,204)=.033, \mathrm{p}=.856$, Familiarity $\mathrm{F}(1,204)=.219, \mathrm{p}=.640$, nor any two- or three-way interactions were found (all p's $>.05$ ). Since there was only an effect of function, we looked at whether responses in the No Function and Function cases differed from the midpoint and found that responses in both the No Function and Function cases were significantly different from the midpoint: No Function, $\mathrm{t}(118)=-5.32, \mathrm{p}<.001$; Function, $\mathrm{t}(86)=2.82, \mathrm{p}<.01$.

${ }^{13} 173$ participants were recruited from Amazon's Mechanical Turk, and randomly assigned to one of six conditions. After reading the case participants were asked to indicated their agreement, on a 7 -point scale (anchored with $1=$ completely disagree and $7=$ completely agree), with the following statement: 'Rather than being a bunch of scattered objects that do not in any way compose some one thing, the arrangement of rocks actually compose something.' Participants were then given, on a separate page, two comprehension questions:

1. Jones lives on the side of a mountain (yes/no)

2. Because of the avalanche, rocks were strewn across Jones' lawn (yes/no)

Four people were excluded from the data analysis for failing at least one of the comprehension questions. Analyzing the remaining 169 responses using a two-way analysis of variance, we found a statistically significant large-sized effect of function on people's composition judgments $F$ (1, $169)=46.341, \mathrm{p}=.000, \eta \mathrm{p}^{2}=.362$. Bonferonni post-hoc tests showed that composition judgments across each level of function were significantly different from the others: No Function Conditions $(M=3.05$, $\mathrm{SD}=1.34)$ were significantly different from both the Accorded Function $(\mathrm{M}=5.05, \mathrm{SD}=1.77, \mathrm{p}<.001)$ and Designed Function Conditions $(\mathrm{M}=5.84, \mathrm{SD}=1.52, \mathrm{p}<.001)$, and the Accorded Function Conditions were significantly different from Designed Function Conditions $(\mathrm{p}<.05)$. Moreover, responses in each of the conditions were significantly different from the midpoint: No Function, $t(56)=-3.73$, $\mathrm{p}<.001$; Accorded Function, $\mathrm{t}(50)=4.06, \mathrm{p}<.001$; Designed Function, $\mathrm{t}(63)=14.34, \mathrm{p}<.001$. There was no effect of Naming $\mathrm{F}(1,169)=2.185, \mathrm{p}=.141$ nor was there an interaction between Naming and Function $\mathrm{F}(2,169)=.533, \mathrm{p}=.588$.

${ }^{14} 75$ participants were recruited from Amazon's Mechanical Turk, and randomly assigned to one of two conditions. After reading the case, participants were given two response options:

a. When Jones tied the pieces of rope together, he created a single, unified object out of the rope

b. When Jones tied the pieces of rope together, he did not create a single, unified object out of the rope. Rather, he simply had two, distinct pieces of rope

After answering, they were then asked, on a separate page, two comprehension questions:

1. Jones was trying to move a water heater (yes/no)

2. Jones was able to move the water heater (yes/no)

Seven people were excluded from the data analysis for failing at least one of the comprehension questions. Analyzing the remaining 68 responses, we found that whether or not the rope successfully 
fulfilled its function had a statistically significant small-sized effect on whether people said that the rope was a single, unified rope or two separate pieces of rope, $\mathrm{X}^{2}(68)=4.769, \mathrm{p}=.029$, Cramer's $\mathrm{V}=.265$.

${ }^{15}$ When we say that success tends to be required, we mean to remain neutral on whether the thing in question might survive a later failure to serve its function. Contrast (i) a botched watch that never worked, with (ii) a broken watch that initially worked but later broke. We suspect that most people would deny that the botched watch is really a watch (it's just a collection of cogs and gears that doesn't really do anything), but may well uphold that the broken watch is still a watch if it can easily be fixed so as to resume its successful performance. See Rose (2015) for empirical evidence that folk judgments of persistence through time are tied to preservation of function.

${ }^{16}$ We ran several further studies attempting to get further inside the folk notion of function, which considerations of space prevent us from detailing here (for an expanded version of this paper including these further studies see Rose \& Schaffer forthcoming:, espec. §4). Overall we found a fairly complicated interaction between accorded versus designed function, and success versus failure. When something is both designed to serve a certain purpose and succeeds at that purpose, then it seems that people will tend to lock onto that purpose in saying what a thing is as well as what it is for. But when the thing is accorded a different purpose after the fact, and only succeeds at that accorded purpose, then it seems that people may lock onto that accorded purpose in saying what a thing is as well as what it is for, at least so long as the lack of a (successful) designed function is not sufficiently emphasized.

${ }^{17}$ A total of 33 participants were recruited through Amazon's Mechanical Turk. After reading the case and indicating who they agreed with (Liz or Andy: again, using the same 7-point scale as in Handshake above), participants were then taken to a separate page where they answered three comprehension questions:

1. Sally and Tom are leaders of rival political factions (yes/no)

2. Andy thinks that the handshake did not create a larger object (yes/no)

3. Liz thinks that the handshake did create a larger object (yes/no)

Four participants were excluded for missing one or more comprehension questions, which left a total of 29 responses. Overall, participants showed strong agreement with Liz $(\mathrm{M}=1.88, \mathrm{SD}=1.48)$, with responses being significantly below the midpoint $\mathrm{t}(29)=-7.16, \mathrm{p}<.001$.

${ }^{18}$ We thank Jonathan Weinberg for this point.

${ }^{19}$ At this point we join Goldman (2007), Paul (2010), and Schaffer (forthcoming) in thinking that cognitive science can prove relevant to real metaphysics, if only to teach us which intuitions should be ignored. As Goldman (2007: 2) explains: 'Cognitive organs or mechanisms play a critical role in the causal production of appearances, including metaphysical appearances (whatever exactly we take that to connote). In considering whether such metaphysical appearances should be accepted at face value or, alternatively, should be superseded through some sort of metaphysical reflection, it obviously makes sense to be as informed as possible about how these mechanisms of cognition work. That is why cognitive science is relevant.'

${ }^{20}$ Our discussion of reactions is not intended to be exhaustive. For instance, we will not consider the reaction of attempting to revive teleological thinking. See Hawthorne \& Nolan (2006) for further discussion, as well as Bowers (manuscript) for a more optimistic attempt at revival.

${ }^{21}$ See Bennett (2009) and Kriegel (2013) for defenses of skeptical views on the composition debate. Both Bennett and Kriegel accept that there is a meaningful special composition question, and merely recommend withholding belief as to which is the right answer. Though of course there is also room for a skeptical view that denies that the special composition question is even meaningful.

${ }^{22}$ We follow Kahane (2011: 106) in associating undermining defeaters and debunking explanations: 'Debunking arguments are arguments that show the causal origins of a belief to be an undermining defeater.' See Mason (2010) for a useful overview of the structure of debunking arguments.

${ }^{23}$ Thanks to Jason Bowers, Andrew Higgins, Joshua Knobe, Dan Korman, Uriah Kriegel, Jonathan Livengood, Ned Markosian, David McElhoes, Shaun Nichols, Laurie Paul, Angel Pinillos, John Turri, Jonathan Weinberg, audiences at Buffalo and Arizona State, and an anonymous Noûs referee. 


\section{References}

Allen, Colin and Marc Bekoff 1995. Function, Natural Design, and Animal Behavior: Philosophical and Ethological Considerations. Perspectives in Ethology, Vol. 11: Behavioral Design, ed. N. S. Thompson: 1-47. Plenum Press.

Aristotle 1984a. Physics. The Complete Works of Aristotle, Vol. 1, ed. Jonathan Barnes: 315-446. Princeton University Press.

— 1984b. Metaphysics. The Complete Works of Aristotle, Vol. 2, ed. Jonathan Barnes: 1552-728. Princeton University Press.

Atran, Scott 1998. Folk Biology and the Anthropology of Science: Cognitive Universals and Cultural Particulars. Behavioral and Brain Sciences 21: 547-609.

Bacon, Francis 1996. Collected Works of Francis Bacon, vol. 4: Translations of the Philosophical Works, eds. James Spedding, Robert Leslie Ellis, and Douglas Denon Heath. Routledge/Thoemmes Press.

Bennett, Karen 2009. Composition, Colocation, and Metaontology. Metametaphysics: New Essays on the Foundations of Ontology, eds. David Chalmers, David Manley, and Ryan Wasserman: 38-76. Clarendon Press.

Bloom, Paul 1996. Intention, History, and Artifact Concepts. Cognition 60: 1-29.

2007. Religion is Natural. Developmental Science 10: 147-51.

Bloom, Paul and Csaba Veres 1999. The Perceived Intentionality of Groups. Cognition 71: B1-B9.

Bowers, Jason manuscript. A Teleological Answer to the Special Composition Question.

Charles, David 2001. Matter and Form: Unity, Persistence, and Identity. Unity, Identity, and Explanation in Aristotle's Metaphysics, eds. Theodore Scaltsas, David Charles, and Mary Louise Gill: 75-106. Clarendon Press.

Cummins, Robert 1975. Functional Analysis. Journal of Philosophy 72: 741-65.

Dawkins, Richard 1995. River out of Eden. Basic Books.

Ellis, Paul 2010. The Essential Guide to Effect Sizes: Statistical Power, Meta-Analysis and the Interpretation of Research Results. Cambridge University Press.

Galli, Leonardo, and Elsa Meinardi 2011. The Role of Teleological Thinking in Learning the Darwinian Model of Evolution. Evolution Education Outreach 4: 145-52.

German, Tim and Susan Johnson 2002. Functions and the Origin of the Design Stance. Journal of Cognition and Development 3: 279-300.

Goldman, Alvin 1993. Philosophical Applications of Cognitive Science. Westview Press.

— 2007. A Program for 'Naturalizing' Metaphysics, with Application to the Ontology of Events. The Monist 90: 457-79.

Gregory, T. Ryan 2009. Understanding Natural Selection: Essential Concepts and Common Misconceptions. Evolution: Education and Outreach 2: 156-75.

Guthrie, Stewart 1993. Faces in the Clouds: A New Theory of Religion. Oxford University Press.

Hawthorne, John and Daniel Nolan 2006. What Would Teleological Causation Be? Metaphysical Essays: 265-84. Clarendon Press.

Heider, Fritz and Marianne Simmel 1944. An Experimental Study of Apparent Behavior. American Journal of Psychology 57: 243-59.

Hirsch, Eli 2002. Quantifier Variance and Realism. Philosophical Issues 12: 51-73.

Hoffman, Joshua and Gary Rosenkrantz 1997. Substance: Its Nature and Existence. Routledge.

Jenkins, C. S. and Daniel Nolan 2008. Backwards Explanation. Philosophical Studies 140: 103-15.

Kahane, Guy 2011. Evolutionary Debunking Arguments. Noûs 45: 103-25.

Kaiser, Mary, Michael McCloskey, and Dennis Proffitt 1986. Development of Intuitive Theories of Motion: Curvilinear Motion in the Absence of External Forces. Developmental Psychology 22: $67-71$.

Kampourakis, Kostas and Vasso Zogza 2008. Students' Intuitive Explanations of the Causes of Homologies and Adaptations. Science and Education 17: 27-47.

Keil, Frank 1995. The Growth of Causal Understandings of Natural Kinds. Causal Cognition: A Multidisciplinary Debate, eds. Dan Sperber, David Premack, and Ann James Premack: 234 62. Oxford University Press. 
Kelemen, Deborah 1999a. The Scope of Teleological Thinking in Preschool Children. Cognition 70: $241-72$.

— 1999b. Why are Rocks Pointy? Children's Preference for Teleological Explanations of the Natural World. Developmental Psychology 35: 1440-52.

— 2004. Are Children 'Intuitive Theists'? Reasoning about Purpose and Design in Nature. Psychological Science 15: 295-301.

2012. Teleological Minds: How Natural Intuitions about Agency and Purpose Influence Learning about Evolution. Evolution Challenges: Integrating Research and Practice in Teaching and Learning about Evolution, eds. Karl S. Rosengren, Sarah K. Brem, E. Margaret Evans and Gale M. Sinatra: 66-92. Oxford University Press.

Kelemen, Deborah and Cara DiYanni 2005. Intuitions about Origins: Purpose and Intelligent Design in Children's Reasoning about Nature. Journal of Cognition and Development 6: 3-31.

Kelemen, Deborah and Evelyn Rosset 2009. The Human Function Compunction: Teleological Explanation in Adults. Cognition 111: 138-43.

Kelemen, Deborah, Joshua Rottman, and Rebecca Seston 2013. Professional Physical Scientists Display Tenacious Teleological Tendencies: Purpose-Based Reasoning as a Cognitive Default. Journal of Experimental Psychology: General 142: 1074-83.

Korman, Dan 2008. Unrestricted Composition and Restricted Quantification. Philosophical Studies 140: $319-34$.

2009. Eliminativism and the Challenge from Folk Belief. Noûs 43: 242-64.

Koslicki, Kathrin 2008. The Structure of Objects. Oxford University Press.

Kriegel, Uriah 2011. Two Defenses of Common-Sense Ontology. Dialectica 65: 177-204.

- 2013. The Epistemological Challenge of Revisionary Metaphysics. Philosopher's Imprint 13: 1-30.

Lewis, David 1986. On the Plurality of Worlds. Basil Blackwell.

1991. Parts of Classes. Basil Blackwell.

Lombrozo, Tania and Susan Carey 2006. Functional Explanation and the Function of Explanation. Cognition 99: 167-204.

Lombrozo, Tania, Deborah Kelemen, and Deborah Zaitchik 2007. Inferring Design: Evidence for a Preference for Teleological Explanation in Patients with Alzheimer's Disease. Psychological Science 18: 999-1006.

Machery, Edouard 2012. Power and Negative Results. Philosophy of Science 79: 808-20.

Markosian, Ned 1998. Brutal Composition. Philosophical Studies 92: 211-49.

— 2014. A Spatial Approach to Mereology. Mereology and Location, ed. Shieva Kleinschmidt: 69-90. Oxford University Press.

Mason, Kelby 2010. Debunking Arguments and the Genealogy of Religion and Morality. Philosophy Compass 5: 770-8.

Matan, Adee and Susan Carey 2001. Developmental Changes within the Core of Artifact Concepts. Cognition 77: 1-26.

Merricks, Trenton 2001. Objects and Persons. Clarendon Press.

Millikan, Ruth 1989. In Defense of Proper Functions. Philosophy of Science 56: 288-302.

Moore, Rob, Gill Mitchell, Rod Bally, Margaret Inglis, Jennifer Day and David Jacobs 2002. Undergraduates' Understanding of Evolution: Ascription of Agency as a Problem for Student Learning. Journal of Biological Education 36: 65-71.

Paul, L. A. 2010. A New Role for Experimental Work in Metaphysics. Review of Philosophy and Psychology 1: 461-76.

Pollock, John 1987. Defeasible Reasoning. Cognitive Science 11: 481-518.

Rea, Michael 1998. In Defense of Mereological Universalism. Philosophy and Phenomenological Research 58: 347-60.

Rips, Lance 1989. Similarity, Typicality and Categorization. Similarity and Analogical Reasoning, eds. Stella Vosniadou and Andrew Ortony: 21-59. Cambridge University Press.

Rose, David 2015. Persistence through Function Preservation. Synthese 192: 97-146.

Rose, David and Jonathan Schaffer forthcoming. Folk Mereology is Teleological. Experimental Metaphysics, ed. David Rose. Bloomsbury. 
Rosen, Gideon and Cian Dorr 2002. Composition as a Fiction. The Blackwell Companion to Metaphysics, ed. Richard Gale: 151-74. Basil Blackwell.

Sanford, David 1993. The Problem of the Many, Many Composition Questions, and Naïve Mereology. Noûs 27: 219-28.

Schaffer, Jonathan 2009. On What Grounds What. Metametaphysics: New Essays on the Foundations of Ontology, eds. David Chalmers, David Manley, and Ryan Wasserman: 347-83. Clarendon Press.

_ forthcoming. Cognitive Science and Metaphysics: Partners in Debunking. Goldman and his Critics, eds. Hilary Kornblith and Brian McLaughlin. Wiley-Blackwell.

Sider, Theodore 2013. Against Parthood. Oxford Studies in Metaphysics 8, eds. Karen Bennett and Dean Zimmerman: 237-93. Oxford University Press.

Simons, Peter 1987. Parts: A Study in Ontology. Clarendon Press.

Thomasson, Amie 2007. Ordinary Objects. Oxford University Press.

van Inwagen, Peter 1990. Material Beings. Cornell University Press. 